\title{
Sociological limitations of the climate change encyclical.
}

\author{
Wright, Erik Olin.
}

Cita:

Wright, Erik Olin (2015). Sociological limitations of the climate change encyclical. Nature Climate Change, 5, 902-903.

Dirección estable: https://www.aacademica.org/erik.olin.wright/2 ARK: https://n2t.net/ark:/13683/paqp/800 

climate change encyclical

\author{
Erik Olin Wright
}

\title{
The Pope has articulated a need to change the way society thinks about economic growth, but it is implausible to rely primarily on moral conversion to solve our environmental and social ills.
}

\section{1} he Pope's encyclical on climate change (http://go.nature.com/7IbiB5), subtitled 'On care for our common home', accepts the scientific consensus that human activity linked to the use of modern technologies has significantly contributed to global warming in particular, and to environmental deterioration more generally. The sociological analysis embedded in the encyclical attempts to explain why people have behaved in this way, why they resist altering their behaviour, and what it would take to change the situation.

One common answer to these questions revolves around economic interests and power. While the encyclical does acknowledge the role of interests, especially those of powerful actors, it argues that interests and power are not the root explanation of the destructive use of technology. Instead, the fundamental explanation of environmentally destructive human activity is found in certain distinctive aspects of contemporary culture.

The basic argument goes like this: contemporary societies, especially in the richer regions of the world, are characterized by a cultural configuration comprising a number of interconnected elements: rampant individualism, anthropocentrism, consumerism, relativism, and what the encyclical calls the technological, technocratic or techno-economic paradigm. What unifies these disparate cultural elements is instrumental reasoning - a form of reasoning that focuses on the most powerful means for achieving goals rather than the ethical status of the goals themselves. This kind of reasoning is a pervasive feature of contemporary culture, characterizing the mindsets of both ordinary people and elites, and contrasts with ethical reasoning anchored in concern about the intrinsic moral qualities of actions.

The central sociological thesis of the encyclical is that instrumental reasoning, particularly because it is embodied in the technological paradigm, makes people indifferent to the negative environmental side effects of economic growth and technological development. It also makes people indifferent to social injustice and the deterioration of the social environment: "The same mindset which stands in the way of making radical decisions to reverse the trend of global warming also stands in the way of achieving the goal of eliminating poverty" (\$175). When instrumental reasoning becomes the overarching cognitive orientation of a culture, people develop attitudes that lead them to engage in practices that systematically harm both the natural environment and social environment in which they live. This mindset becomes particularly destructive when it is combined with concentrations of economic and political power.

\section{Cultural transformation}

Given this diagnosis of the problem, the encyclical argues that crucial cultural transformations are needed: "The problem is that we still lack the culture needed to confront this crisis" (\$53) and "[all] of this shows the urgent need for us to move forward in a bold cultural revolution" (\$114). The heart of this revolution is a new cultural configuration that subordinates instrumental reasoning to ethical reasoning and places the well-being of others and the natural environment at the centre of human concerns.

Without this new culture, efforts at creating new public policies to deal with the environmental crisis will fail because "If the laws are to bring about significant, longlasting effects, the majority of the members of society must be adequately motivated to accept them, and personally transformed to respond. Only by cultivating sound virtues will people be able to make a selfless ecological commitment" (\$211). While the encyclical also states that "Unless citizens control political power - national, regional and municipal - it will not be possible to control damage to the environment," (\$179), this will only contribute to a just world and a healthy environment if citizens and elites have been liberated from the technocratic paradigm.

Transforming culture, of course, is no simple task. Two principle kinds of obstacles are discussed in the encyclical. First, elites actively obstruct efforts at change both because they themselves have a mindset trapped in the matrix of instrumental reasoning and because their privileges and power are sustained by the cultural diffusion of that mindset. Second, ordinary people have been socialized and educated into the instrumental attitude and seduced by consumerism and individualism: "compulsive consumerism is one example of how the techno-economic paradigm affects individuals.... This paradigm leads people to believe that they are free as long as they have the supposed freedom to consume" (\$203).

In spite of the strength of socialization into the dominant culture and the powerful interests opposed to change, the encyclical still argues that a cultural revolution is possible. The key idea in the encyclical that opens up space for this possibility is a proposition about two inherent properties of human beings - their capacity for moral reasoning and feelings, and their capacity to reflect on their own beliefs and change them: "Yet all is not lost. Human beings, while capable of the worst, are also capable of rising above themselves, choosing again what is good, and making a new start, despite their mental and social conditioning. We are able to take an honest look at ourselves, to acknowledge our deep dissatisfaction, and to embark on new paths to authentic freedom. No system can completely suppress our openness to what is good, true and beautiful, or our God-given 
ability to respond to his grace at work deep in our hearts." (\$205)

This capacity for self-transformation enables people to hear messages and have experiences that contradict their existing mindset, and this opens the door for strategies of cultural change. The basic idea is to touch people in ways that challenge the dominant attitude, provide them with alternative understandings of the world, and stimulate the kind of self-reflection needed to form a new mindset imbued with a spirit of "tenderness, compassion and concern for our fellow human beings" ( $\$ 91)$. The process by which this actually happens is referred to in the encyclical as "profound interior conversion” (\$217).

\section{Limits}

The encyclical provides a powerful indictment of the social practices that have contributed to environmental and social degradation, and a passionate call for radical transformation of our relationship to nature. However, its overall account is limited in several important ways.

First, while the encyclical certainly recognizes the ways in which markets, business practices and state policies have contributed to environmental degradation, these are treated mainly as an expression of the relentless operation of instrumental reasoning and its connected cultural forms. These cultural forms are the critical underlying social causes of the processes that damage the environment and perpetuate social injustice. An alternative view would treat the capitalist structure of the economy and the weakly democratic structure of the state as not simply an expression of some underlying cultural paradigm, but as relatively autonomous causal processes in their own right.

The fact that capitalist firms pursue short-term profits in ways that ignore environmental externalities is not simply because the executives of those firms have a particular mindset; it is because of the dynamics of competition and the nature of power relations within a capitalist economy. Similarly, the absence of effective state actions is mainly due to the deep intertwining of economic power and state power. The mindsets of capitalists, managers and political officials are to a significant extent a consequence of the structure and operation of a capitalist economy and political system rather than an autonomous explanation for that operation. The implication is that in order for the aspirations of the encyclical to be realized, the fundamental task is to transform these systems.

Second, once it is recognized that to solve the environmental crisis the

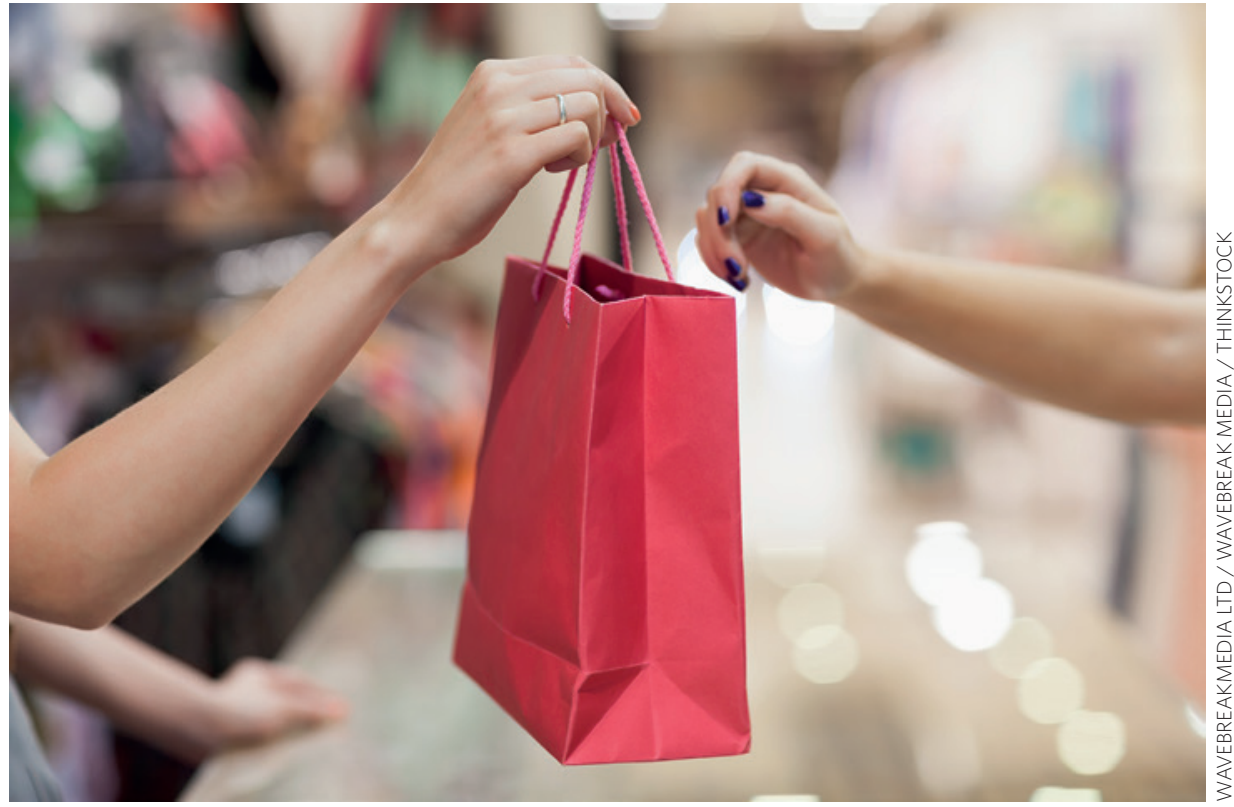

structures of power within the capitalist economy and state need to be transformed, it becomes implausible that this can be accomplished by a cultural revolution of the mindsets of elites. The powerful interests that are opposed to genuinely restoring ecological balance and seriously dealing with global poverty need to be defeated through political confrontation, rather than simply converted to a more compassionate, ethically grounded mindset. Even if some individual rich and powerful people do reject the dominant culture, the hope for such conversion on a wide scale within the elite is not a credible strategy. Political mobilization needs to be part of the strategy, and as part of such mobilization one can expect fairly sharp conflicts to occur, with winners and losers. Except for a few passing references to citizen pressure $(\$ 179,206)$, and efforts of the ecological movement (\$166), the encyclical is silent on the need for mobilized confrontation.

Finally, if the moral goals of the encyclical require challenging the power structures of capitalism and the state, then effective forms of collective capacity to carry out such challenges must be developed. The encyclical says nothing on this issue. The implicit theory in the encyclical is that cultural change, if widespread, more or less automatically gets translated into the necessary collective action for institutional change. The encyclical states "there needs to be a distinctive way of looking at things ... which together generate resistance to the assault of the technocratic paradigm." (\$107). There is, however, no discussion of the necessary political vehicles for translating new ways of thinking into effective collective action. No theory of the capacity for struggle is presented, only the desire for alternatives.

This is a classic gap in social analyses - a description of grievances is seen as sufficient to explain conflict. In such accounts, the problem of aggregating grievances of individuals into a collectively effective form of struggle disappears. But as we know from countless studies, grievances often fail to generate action for many reasons. In particular, in the world today, changes in public opinion are not smoothly translated into public policy because of failures to solve the organizational problems of political action even in relatively democratic political systems. What we need is a theory of collective organization - social movements, political parties, unions - and how these mobilize (or fail to mobilize) people for collective action.

The challenge of our age includes the themes articulated in the encyclical: cultural transformation to raise awareness of the ethical issues in our relationships to nature and society, efforts to undermine the power of consumerism and rampant individualism to define the horizons of action, and so on. But if we are to effectively realize the emancipatory values of social justice, democracy, community and sustainability, we also need to challenge dominant structures of power and privilege in capitalist society. For this to succeed, we need more than moral conversion.

Erik Olin Wright is in the Department of Sociology, University of Wisconsin-Madison, Madison, Wisconsin 53706, USA.e-mail:wright@ssc.wisc.edu 